\title{
Multicomponent Stereoselective Polymerizations toward Multifunctional AIE Polymers with $\alpha, \beta$-Unsaturated Amidines
}

\author{
Xiang Su, ${ }^{\dagger, \ddagger, \S}$ Niu Niu, ${ }^{\dagger, \ddagger}$ Haoxuan Li, ${ }^{\dagger, \ddagger, \S}$ Ting Han, ${ }^{*, \dagger}$ Dong Wang, ${ }^{*, \dagger}$ Ben Zhong Tang*,§,\| \\ ${ }^{\dagger}$ Center for AIE Research, Shenzhen Key Laboratory of Polymer Science and Technology, Guangdong Research \\ Center for Interfacial Engineering of Functional Materials, College of Materials Science and Engineering, Shenzhen \\ University, Shenzhen 51806o, China \\ ${ }^{\ddagger}$ College of Physics and Optoelectronic Engineering, Shenzhen University, Shenzhen 518060, China \\ $\S$ Department of Chemistry, Hong Kong Branch of Chinese National Engineering Research Center for Tissue \\ Restoration and Reconstruction, The Hong Kong University of Science and Technology, Clear Water Bay, Kowloon, \\ Hong Kong, China
}

\|Shenzhen Institute of Aggregate Science and Technology, School of Science and Engineering, The Chinese University of Hong Kong, Shenzhen, Guangdong 518172, China

KEYWORDS. multicomponent polymerization, heterochain polymer, aggregation-induced emission

\begin{abstract}
Heterochain polymers play an essential role in our daily lives due to their distinctive properties. Among various heteroatom-rich structures, amidine derivatives serve as a synthetically important and pharmacologically useful structural branch and have found wide applications in synthetic chemistry and biomedicine field. In this work, we developed a straightforward and powerful polymerization tool to access diverse heterochain polymers with $\alpha, \beta$-unsaturated amidine units. The multicomponent electrophilic polymerizations of readily accessible diynes, disulfonyl azides, and $N, N$-dimethylformamide dimethyl acetal proceed efficiently at room temperature, producing amidine-containing polymers with high molecular weights ( $M_{\mathrm{w}}$ up to 74500$)$ in high yields within merely $1 \mathrm{~h}$. Nuclear magnetic resonance spectra analysis revealed that all the obtained polymers are formed with excellent stereoselectiviy. The introduction of aggregation-induced emission (AIE) luminogen together with the inherent heteroatom-rich structure feature endow these polymers with multiple functionalities. The nanoaggregates of the diethylamino-substituted polymer show remarkable and reversible fluorescence response to acid and base, and the acid-fumed polymer thin film can be used as a sensitive and reusable fluorescent probe for detecting seafood spoilage. This polymer system can also be employed as a highly selective and sensitive $\mathrm{Au}^{3+}$ sensor, and efficient gold recovery can be achieved based on the excellent gold enrichment capability of the polymer. In addition, the AIE polymers can also be applied in lysosome-specific cell imaging with low cytotoxicity and excellent photostability.
\end{abstract}

\section{INTRODUCTION}

Heterochain polymers are abundant in nature and play an important role in our daily lives. For instance, most of biomacromolecules that are essential for life are rich in heteroatoms, such as DNAs, proteins and enzymes. The presence of nitrogen, oxygen, sulfur or phosphorus are crucial for these biomacromolecules to function well in many significant biological behaviors. ${ }^{[1-4]}$ On the other hand, synthetic heterochain polymers have greatly advanced the development of polymer science and materials industry. The inclusion of multiple heteroatoms into polymer backbones can endow polymeric materials with distinctive chemical, thermal, optoelectronic, and mechanical properties and thus benefit their practical applications. Till now, heteroatom-rich polymers have been widely used in water treatment, flame retardants, stimuli-responsive materials, fluorescent sensors, photoelectronic devices, etc. ${ }^{[5-9]}$ Therefore, the construction of heteroatom-rich polymeric materials with unique structures and advanced functionalities is attractive due to their great significance in both academic and industrial fields.

Amidine derivatives are a branch of synthetically important and pharmacologically useful heteroatom-rich structures. Materials with amidine structures often possess special chemical, biological and pharmacological activities, and have found diverse applications in synthetic chemistry and biomedicine field. For instance, sulfonyl amidine compounds have been utilized as bioactive pharmacophores with antitumor, ${ }^{[10-11]}$ antiresorptive ${ }^{[12-13]}$ and antiproliferative ${ }^{[14]}$ properties or as 
capture agents of carbon dioxide. ${ }^{[15]}$ The incorporation of amidine unit into polymer structures could combine the merits of amidine structure and the inherent advantages of polymer together to produce multifunctional polymeric materials. Following the technological significance of amidine-containing polymers is their synthetic difficulties. Traditional amidine-containing polymers were often prepared by embedding amidine group into the side chain of polymer frameworks, ${ }^{[16]}$ which generally require tedious synthetic procedures. In the past decade, one-pot multicomponent polymerizations (MCPs) which are derived from multicomponent reactions (MCRs) ${ }^{[17-20]}$ have attracted increasing focus due to their advantages of simple operations, high atom economy, mild reaction conditions, high efficiency, and structural diversity. ${ }^{[21-22]}$ Attracted by these advantages, polymer scientists have developed various powerful MCPs for the synthesis of heteroatom-rich polymers with complicated structures and diverse functionalities. ${ }^{[23-31]}$ Among them, the copper-catalyzed polymerizations of alkyne, sulfonyl azide and different nucleophiles are an attractive and representative group of MCPs that can efficiently construct amidine-containing polymers. ${ }^{[32-36]}$ For example, Choi and Tang et al. have successfully synthesized various high-molecular-weight poly( $\mathrm{N}$-sulfonylamidines) from the MCPs of alkynes, sulfonyl azides, and diamines. ${ }^{[32-34]}$ Also, Tang and Hu et al. have reported a copper-catalyzed MCP of alkynes, sulfonyl azides, and iminophosphorane to prepare heteroatom-rich poly(phosphorus amidine)s. ${ }^{[36]}$ The possible reaction mechanism of such MCPs commonly involves a critical reactive ketenimine intermediate that is in situ generated by the $\mathrm{Cu}$-catalyzed reaction of alkyne and sulfonyl azide. Theoretically, the resonance structure of ketenimine intermediate could be attacked by both nucleophiles and electrophiles. However, the subsequent transformations of ketenimine intermediate in previously reported MCPs mainly fastened on the addition of various nucleophiles to the central carbon of ketenimine. ${ }^{[32-34,37-39]}$ while MCPs based on the electrophilic addition of electrophiles to ketenimine intermediates have rarely been reported.

Recently, a Cu-catalyzed three-component reaction of alkyne, sulfonyl azide, and $N, N$-dialkyloxyformamide dialkyl acetal drew our attention (Scheme $1 \mathrm{~A}$ ). ${ }^{[40]}$ This MCR can prepare a variety of pharmacologically useful unsaturated amidines with excellent stereoselectivity in high yields under mild conditions. The plausible mechanism indicated that this MCR might involve an distinctive electrophilic addition of immonium ion (intermediate A) to the copper ketenimine (intermediate $\mathrm{B})$, and the immonium ion intermediate was generated in situ via the elimination of $\mathrm{MeOH}$ between terminal alkynes with $N, N$-dimethylformamide dialkyl acetals (Scheme $1 \mathrm{~A}$ and Scheme $\left.\mathrm{S}_{1}\right)^{[41]}$ In this work, we successfully developed this MCR into a stereoselective electrophilic MCP to benefit the synthesis of multifunctional heterochain polymers. As shown in Scheme $1 \mathrm{~B}$, through the facile $\mathrm{Cu}(\mathrm{I})$-catalyzed polymerizations of readily accessible diynes, disulfonyl azides, and $N, N$-dimethylformamide dimethyl acetal, a series of high molecular weight polymers bearing $\alpha, \beta$-unsaturated amidine units were produced in high yields within merely $1 \mathrm{~h}$. Numerous heteroatoms including $\mathrm{N}, \mathrm{O}$, and $\mathrm{S}$ were readily integrated into polymer skeletons in a one-pot fashion at room temperature. Moreover, this electrophilic MCP is highly stereoselective, producing a series of stereoregular heterochain polymers with multiple functionalities. Based on the remarkable acid-responsive fluorescence of the obtained polymers, the acidified polymer films can be used for the sensitive detection of seafood spoilage. Besides, they can also be applied in the sensitive and selective detection of $\mathrm{Ru}^{3+}$ or $\mathrm{Au}^{3+}$ and efficient gold recovery as well as in lysosome-specific cell imaging.

Scheme 1. (A) Multicomponent Reaction via Electrophilic Addition of Immonium Ion to Copper Ketenimine. (B) Multicomponent Polymerizations toward Functional Polymers with $\alpha, \beta$-Unsaturated Amidines.

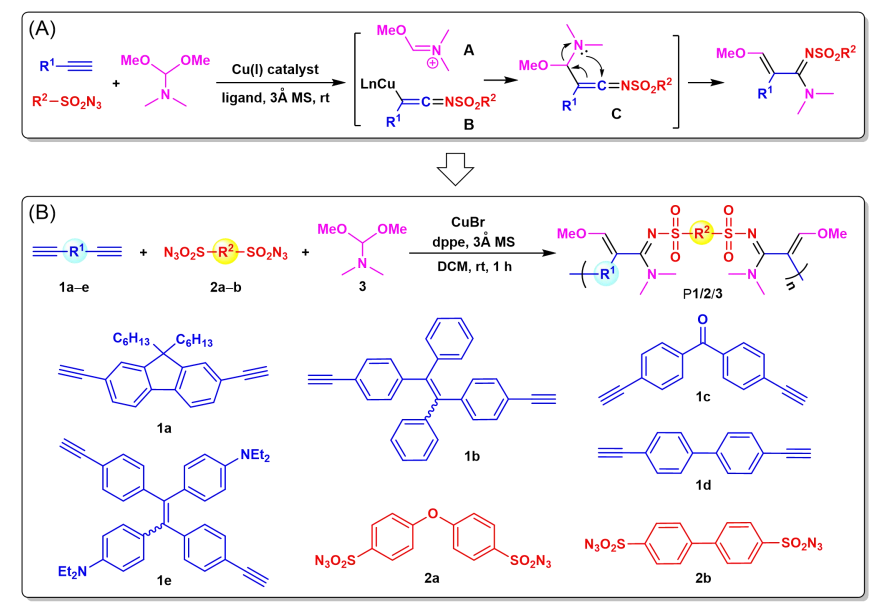

\section{RESULTS AND DISCUSSION}

\section{Polymerization}

To investigate the polymerizability of diyne, disulfonyl azide and $N, N$-dialkyloxyformamide dialkyl acetal, we first selected the readily accessible $\mathbf{1 a}$ and $\mathbf{2 a}$ and commercially available 3 as model monomers to optimize the polymerization conditions. On the first try, the polymerization of $\mathbf{1 a}$, $\mathbf{2 a}$ and $\mathbf{3}$ was carried out in dichloromethane (DCM) under $\mathrm{N}_{2}$ at room temperature in the presence of $\mathrm{CuI}(2 \mathrm{O} \mathrm{mol} \%)$, 1,2-bis(diphenylphosphino)ethane (dppe, $20 \mathrm{~mol} \%$ ), and 3 Å MS (molecular sieves, $40 \mathrm{mg}$ ), and the monomer molar ratio of [1a]:[2a]:[3] was 1:1:2 at a monomer concentration of $[\mathbf{1 a}]=0.1 \mathrm{M}$. After reacting for $1 \mathrm{~h}$, high molecular weight polymeric product $\left(M_{\mathrm{n}}=25300 ; M_{\mathrm{w}}=41000\right)$ was obtained in a high yield of $90 \%$ (Table 1 , entry 1 ). Further extending the reaction time from $1 \mathrm{~h}$ to $12 \mathrm{~h}$ led to the formation of insoluble polymer gels. The exposure of air was unfavorable for this polymerization, because an 
obvious decrease was observed in both reaction yield $(78 \%)$ and molecular weights $\left(M_{\mathrm{w}}=17700\right)$ (Table 1 , entry 2). We then investigated the effect of phosphine ligand on the polymerization of $\mathbf{1 a}, \mathbf{2 a}$ and 3 under $\mathrm{N}_{2}$ atmosphere (Table 1, entries 3-6). The results suggested that the addition of dppe ligand facilitated this MCP. The polymerization without the use of dppe resulted in a decreased reaction yield of $74 \%$ although the molecular weights were increased. Neither increasing nor decreasing the feed of dppe could improve the polymerization results. Replacing dppe with $\mathrm{PPh}_{3}$ led to a much lower yield of $66 \%$ and a larger PDI. With the optimized ligand condition, we next examined the catalyst effect and the results showed that the use of $20 \mathrm{~mol} \% \mathrm{CuBr}$ displayed the best reactivity among the tested conditions (Table 1 , entries 1 and 7-10). According to the proposed reaction mechanism, the addition of $3 \AA$ MS could help assimilate the in situ released methanol and thus is beneficial to the smooth polymerization. Indeed, the absence of $3 \AA$ MS significantly reduced the polymerization efficiency (Table 1, entry 11). Changing the amount of $3 \AA$ MS had little effect on the reaction yield but provided lower molecular weights (Table 1, entries 12 and 13). Therefore, the addition of $40 \mathrm{mg} 3 \AA$ MS was taken as the most suitable additive condition for the following investigation. The solvent screening results shown in Table Si suggested that DCM was the best choice among the tested solvents. Other commonly used solvents such as DCE and THF were also fit for the occurrence of this MCP, but the polymerization efficiency is not as high as in DCM. The polymerization in toluene merely gave a trace amount of products. Finally, the effect of monomer feed ratio on the MCP of 1a, 2a and 3 was investigated. As shown in entries 14 and 15 of Table 1 , increasing the monomer molar ratio of $[\mathbf{1 a}]:[\mathbf{2 a}]:[3]$ from $1: 1: 2$ to $1: 1: 2.2$ or $1: 1: 2.4$ improved the reaction yield and $M_{\mathrm{w}}$. Considering both the reaction yield and molecular weights, we preferred to choose 1:1:2.4 as the optimal monomer feed ratio.

Table 1. Optimization of the multicomponent polymerization of 1a, $2 a$ and $3^{a}$

\begin{tabular}{|c|c|c|c|c|c|c|c|}
\hline entry & catalyst (mol\%) & ligand $(\mathrm{mol} \%)$ & $3 \AA ̊ M S(m g)$ & yield (\%) & $M_{\mathrm{n}}^{\mathrm{b}}$ & $M_{\mathrm{w}}^{\mathrm{b}}$ & $\mathrm{PDI}^{\mathrm{b}}$ \\
\hline 1 & $\mathrm{CuBr}(20)$ & dppe (20) & 40 & 90 & 25300 & 41000 & 1.6 \\
\hline $2^{c}$ & $\mathrm{CuBr}(20)$ & dppe (20) & 40 & 78 & 12700 & 17700 & 1.4 \\
\hline 3 & $\mathrm{CuBr}(20)$ & - & 40 & 74 & 35600 & 73900 & 2.0 \\
\hline 4 & $\mathrm{CuBr}(20)$ & dppe (30) & 40 & 85 & 21500 & 33300 & 1.5 \\
\hline 5 & $\mathrm{CuBr}(20)$ & dppe (10) & 40 & 83 & 21100 & 33800 & 1.6 \\
\hline 6 & $\mathrm{CuBr}(20)$ & $\mathrm{PPh}_{3}(20)$ & 40 & 66 & 23700 & 68000 & 2.9 \\
\hline 7 & CuI (20) & dppe (20) & 40 & 70 & 11800 & 15400 & 1.3 \\
\hline 8 & $\mathrm{CuCl}(20)$ & dppe (20) & 40 & 83 & 13100 & 18000 & 1.4 \\
\hline 9 & $\mathrm{CuBr}(30)$ & dppe (20) & 40 & 86 & 20400 & 29000 & 1.4 \\
\hline 10 & $\mathrm{CuBr}(10)$ & dppe (20) & 40 & 78 & 11600 & 15500 & 1.3 \\
\hline 11 & $\mathrm{CuBr}(20)$ & dppe (20) & - & 76 & 13700 & 19100 & 1.4 \\
\hline 12 & $\mathrm{CuBr}(20)$ & dppe (20) & 20 & 88 & 13500 & 18900 & 1.4 \\
\hline 13 & $\mathrm{CuBr}(20)$ & dppe (20) & 60 & 92 & 18400 & 27200 & 1.5 \\
\hline $14^{d}$ & $\mathrm{CuBr}(20)$ & dppe (20) & 40 & 92 & 21800 & 50300 & 2.3 \\
\hline $15^{e}$ & $\mathrm{CuBr}(20)$ & dppe (20) & 40 & 91 & 25300 & 45400 & 1.8 \\
\hline
\end{tabular}

${ }^{a}$ Unless otherwise noted, the polymerizations were carried out under $\mathrm{N}_{2}$ in dichloromethane at room temperature for $1 \mathrm{~h}$, [1a] $=[\mathbf{2 a}]=0.1 \mathrm{M},[3]=0.2 \mathrm{M} \cdot{ }^{b}$ Estimated by GPC in DMF on the basis of a linear polystyrene calibration. PDI $=M_{\mathrm{w}} / M_{\mathrm{n}} \cdot{ }^{c} \mathrm{Under}$ air. ${ }^{d}[3]=0.22 \mathrm{M} .{ }^{e}[3]=0.24 \mathrm{M}$. Abbreviation: dppe = 1,2-bis(diphenylphosphino)ethane.

To explore the scope and versatility of this polymerization strategy and meanwhile enrich the functionalities, we next tested the polymerizability of other monomer combinations under the optimized polymerization condition. As denoted in Scheme $1 \mathrm{~B}$ and Scheme 2, all the tested polymerizations proceeded efficiently at room temperature, affording the target polymers with high $M_{\mathrm{w}} \mathrm{s}$ in high yields. When the more conjugated tetraphenylethylene (TPE)-containing diyne (1b) was used to replace the fluorene-containing diyne (1a), P1b/2a/3 with a $M_{\mathrm{n}}$ of 18300 and a $M_{\mathrm{w}}$ of 28200 was obtained in a high yield of $89 \%$ after reacting for $1 \mathrm{~h}$. Partial gelation occurred after prolonging the reaction time to $12 \mathrm{~h}$ and the soluble portion possessed a much higher molecular weight $\left(M_{\mathrm{n}}=54500 ; M_{\mathrm{w}}=87200\right)$. The electron-deficient diyne 1c with a carbonyl functional group can also effectively polymerize with $\mathbf{2 a}$ and 3, but the polymerization efficiency of 1 c was much lower than those of other tested diynes. When the polymerization was terminated at $1 \mathrm{~h}$, merely oligomers with a $M_{\mathrm{n}}$ of 5300 and a $M_{\mathrm{w}}$ of 9600 was produced in a low yield of $62 \%$. The polymerization results were dramatically improved after reacting for $12 \mathrm{~h}$, resulting in high molecular weight $\mathrm{P1c} / \mathbf{2 a} / 3\left(M_{\mathrm{w}}=74500\right)$ in a high yield $(91 \%)$. The rigid diyne monomer (1d) showed relatively lower reactivity compared to $\mathbf{1 a}$ and $\mathbf{1 b}$, which partially resulted from the 
poorer solubility of $\mathrm{P} \mathbf{1 d} / \mathbf{2 a} / \mathbf{3}$ in DCM due to its rigid structure. To enrich the functionality of the polymers, we also synthesized $\mathrm{N}, \mathrm{N}$-diethyl-substituted TPE-containing diyne (1e) following the synthetic routes shown in Scheme S2, and further tested its reactivity. Delightfully, the polymerization of $\mathbf{1 e}, \mathbf{2 a}$ and $\mathbf{3}$ proceeded smoothly under the optimized conditions, producing polymer P1e/2a/3 in a yield of $90 \%$. Besides $2 \mathbf{a}$, diazide $\mathbf{2 b}$ can also polymerize with $\mathbf{l b}$ and 3 to produce amidine-containing polymeric product with a high $M_{\mathrm{w}}$ in a satisfying yield. In general, the successful construction of P1a-e/2a-b/3 indicated that this MCP route could serve as a straightforward and powerful synthetic tool toward diverse heterochain polymers with $\alpha, \beta$-unsaturated amidines. All the obtained heterochain polymers possessed good solubility in strong polar solvents, such as DMF and DMSO, whereas their solubility in DCM, chloroform and THF was relatively poorer.

Scheme 2. Chemical structures, yields, molecular weights, and the polydispersity of polymers Pra-e/2a-b/3. ${ }^{a}$
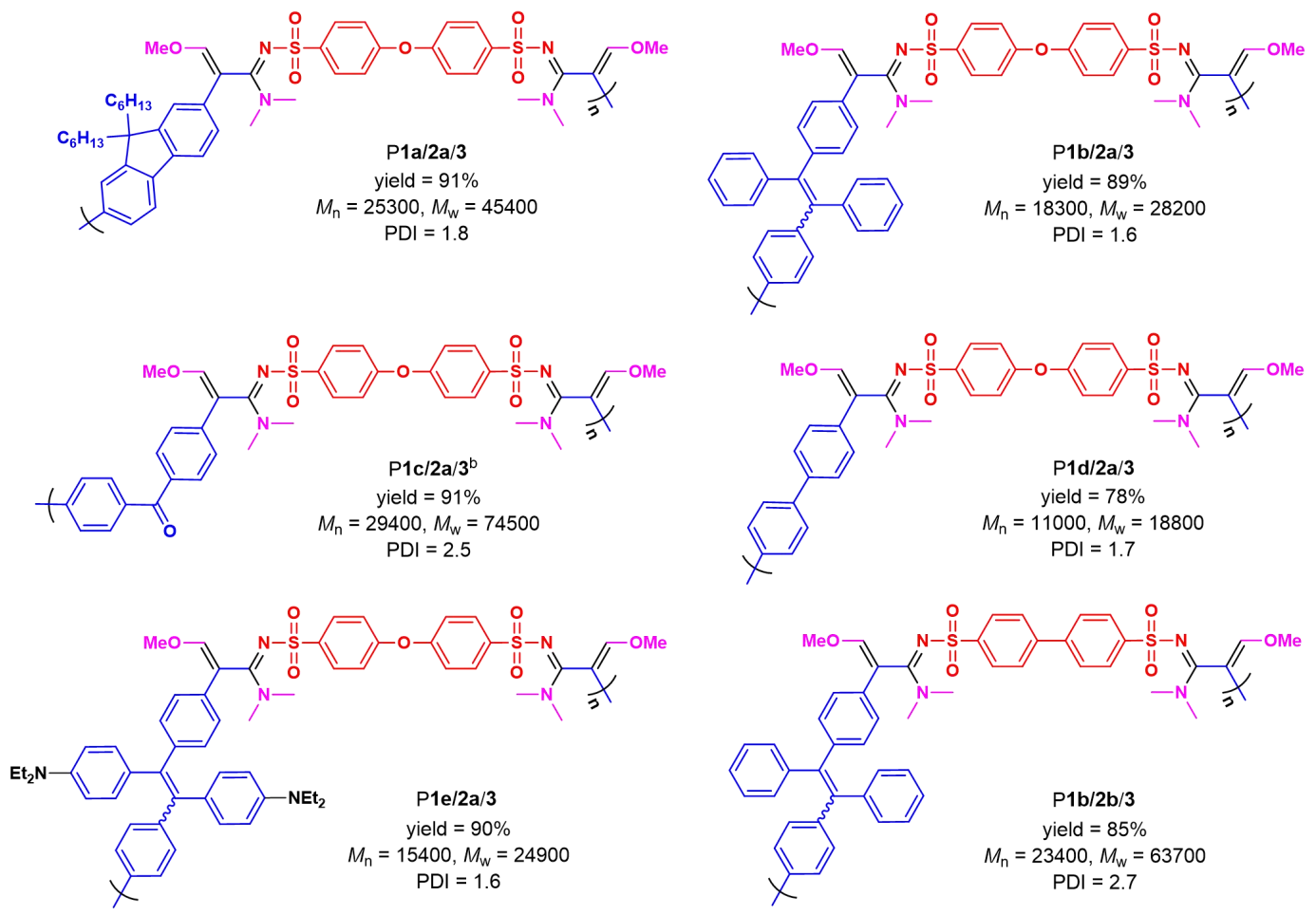

${ }^{a}$ Unless otherwise noted, the polymerizations were carried out in DCM at room temperature in $\mathrm{N}_{2}$ for $\mathbf{1} \mathrm{h},[\mathbf{1 a}]=[\mathbf{2 a}]=0.1 \mathrm{M}$, $[3]=0.24 \mathrm{M}$, dppe (20 mol\%), $3 \AA$ MS (40 mg). ${ }^{\mathrm{b}}$ Polymerization results obtained at $12 \mathrm{~h}$.

\section{Structural Characterization}

For a clear insight into the polymer structures, model compound 4 was synthesized by a one-pot three-component reaction of TPE-substituted alkyne, tosyl azide and 3 (Figure $1 \mathrm{~A}$ ). The structures of model compound 4 and all of the obtained polymers (P1a-e/2a-b/3) were carefully characterized by FT-IR, ${ }^{1} \mathrm{H}$ NMR and ${ }^{13} \mathrm{C}$ NMR. The characterization results suggested that there existed no isomeric structures in compound $\mathbf{4}$ and polymers. According to the XRD structure reported in the related MCR paper, ${ }^{[30]}$ the configuration of the newly formed $\mathrm{C}=\mathrm{C}$ bond adjacent to the amidine group should be in $E$-form.

The detailed characterization results of $\mathrm{P} \mathbf{1 b} / \mathbf{2} \mathbf{a} / \mathbf{3}$ and $\mathbf{4}$ along with the corresponding monomers $\mathbf{1 b}, \mathbf{2 a}$, and $\mathbf{3}$ are illustrated here as an representative example. As shown in Figure $\mathrm{S} 1$, the characteristic absorption peaks related to $\equiv \mathrm{C}-\mathrm{H}$ and $\mathrm{C} \equiv \mathrm{C}$ stretching vibrations of monomer $\mathbf{~} \mathbf{b}$ occurred at 3273 and $2108 \mathrm{~cm}-1$, respectively, and the $\mathrm{N}_{3}$ stretching vibration peaks of $2 \mathrm{a}$ occurred at 2156 and 2127 $\mathrm{cm}^{-1}$. These peaks were not detected in the IR spectra of 4 and $P \mathbf{l b} / \mathbf{2} \mathbf{a} / \mathbf{3}$, indicating the occurrence of expected reactions. Similar conclusion can also be drawn from the NMR analysis. As shown in the Figure $1 B-F$, the ${ }^{1} \mathrm{H}$ NMR spectrum of $\mathrm{Plb} / \mathbf{2 a} / 3$ and model compound 4 showed no resonance signals matching with the peaks of the acetylene protons of $\mathbf{1 b}$ at $\delta$ 3.07-3.03 and the tertiary alkyl proton (d) of 3 at $\delta 4.3$, which further confirmed the complete transformation of monomers during the polymerization. Furthermore, the resonance of aromatic protons at "b" location of 2 a shifted to higher field after polymerization, and the peak associated with methoxy protons (e) of 3 shifted from $\delta 3.29$ to $\delta 3.70$ due to the junction with carbon-carbon double bond after reactions. Meanwhile, the signal at $\delta 2.25$ from the resonance of the methyl protons at "c" position of 3 split into two separate peaks (c') located at $\delta 2.99$ and 2.69 respectively. More importantly, a new peak emerged at $\delta 6.42 \mathrm{ppm}$ in the spectra of 4 and $P 1 b / 2 a / 3$. This peak arose from the resonance of the newly formed "g" proton. The integral ratio of peaks at $\delta 3.70$ and 6.42 in the polymer spectrum 
was calculated to be about 3:1, which is consistent with the expected ratio of " $\mathrm{e}$ " and " $\mathrm{g}$ " protons in the desired polymer.

The ${ }^{13} \mathrm{C}$ NMR results further verified the obtained polymer structure (Figure $1 \mathrm{G}-\mathrm{K}$ ). The acetylene carbon peaks of $\mathbf{1 b}$ and the " $\mathrm{e}$ " carbon of $\mathbf{3}$ disappeared after the polymerization. Simultaneously, a new peak related to the newly formed $\mathrm{C}=\mathrm{N}$ carbon ("i" position) was observed at $\delta$ 164.69 in the polymer spectrum. The resonance signal of the "f" carbon of 3 shifted from 53.34 ppm to $61.84 \mathrm{ppm}$ after the polymerization process, and the methyl carbons of 3 resonating at "g" position divided into two adjacent peaks of "g" carbons in P1b/2a/3's spectrum. Similar variations were also discovered in the IR and NMR spectra of other polymers (Figure $\mathrm{S}_{2}-\mathrm{S}_{12}$ ). All of these results demonstrated that we obtained the exact targeted polymer structures as depicted in Scheme 2. Moreover, these characterization results also confirmed that this electrophilic MCP is highly stereoselective, producing a series of stereoregular heterochain polymers.

The thermal and morphological stability of the obtained polymers were examined by thermogravimetric analysis (TGA) and differential scanning calorimetry (DSC), respectively. As shown in Figure $\mathrm{S}_{13} \mathrm{~A}$, the decomposition temperature $\left(T_{\mathrm{d}}\right)$ of Pra-e/2a-b/3 at $5 \%$ weight loss ranged from $291{ }^{\circ} \mathrm{C}$ to $304{ }^{\circ} \mathrm{C}$, which is indicative of the good thermal stability of the heterochain polymers. The glass transition temperature $\left(T_{\mathrm{g}}\right)$ of these heterochain polymers were in the range of $119^{\circ} \mathrm{C}$ to $204{ }^{\circ} \mathrm{C}$ (Figure $\mathrm{S}_{13} \mathrm{~B}$ ). The high $T_{\mathrm{g}}$ value of $\mathrm{P} \mathbf{1 b} / \mathbf{2} \mathbf{b} / 3$ at $204{ }^{\circ} \mathrm{C}$ might be due to its relatively rigid backbone structure.
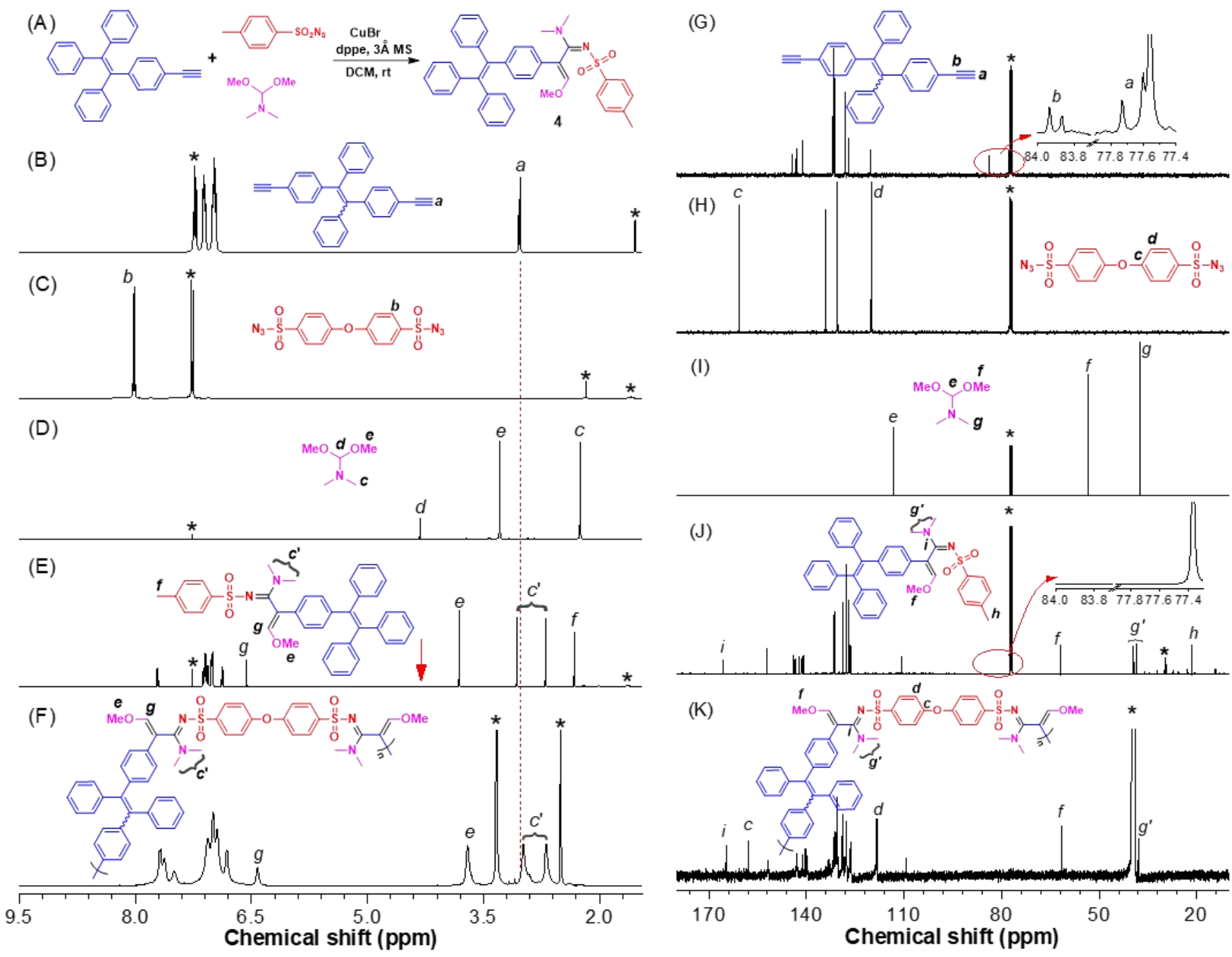

Figure 1. (A) Synthetic route to model compound 4. (B-F) ${ }^{1} \mathrm{H}$ NMR spectra of (B) 1a, (C) 2a, (D) 3, and (E) model compound 4 in $\mathrm{CDCl}_{3}$, and (F) Prb/2a/3 in DMSO. (G-K) ${ }^{13} \mathrm{C}$ NMR spectra of $(\mathrm{G}) \mathbf{1 a},(\mathrm{H}) \mathbf{2 a},(\mathrm{I}) \mathbf{3}_{3}$, and (J) model compound 4 in $\mathrm{CDCl}_{3}$, and (K) $\mathrm{P} \mathbf{1 b} / \mathbf{2 a} / \mathbf{3}$ in DMSO. The solvent peaks are marked with asterisks.

\section{Aggregation-Induced Emission}

The absorption and photoluminescence (PL) properties of the obtained polymers were carefully investigated with the assistance of model compound 4. As depicted in Figure $S_{1}$, the maximum absorption wavelength $\left(\lambda_{\mathrm{abs}, \max }\right)$ of model compound $\mathbf{4}$ and polymers located in the range 
of 317-392 nm. Compared with other polymers, P1e/2a/3 showed the longest $\lambda_{\mathrm{abs} \text { max }}$ at $392 \mathrm{~nm}$ due to the introduction of electron-donating diethylamino group into the aromatic alkyne unit.

Materials with aggregation-induced emission (AIE) properties have drawn great attention due to their efficient solid-state emission, multiple stimuli responses and excellent photostability. ${ }^{[42-45]}$ Serving as a representative AIE motif, TPE was strongly emissive in aggregates or solid state due to the restriction of intramolecular motion, but barely emissive in dilute solutions. ${ }^{[46-49]}$ With the presence of TPE unit in structures, we then investigated the potential AIE properties of model compound $4, \quad \mathrm{P} \mathbf{1 b} / \mathbf{2} \mathbf{a}-\mathbf{b} / \mathbf{3}$ and $\mathrm{P} \mathbf{1 e} / \mathbf{2 a} / \mathbf{3}$ in dilute DMF solutions and DMF/water mixtures. As shown in Figure $2 \mathrm{~A}-\mathrm{C}$ and Figure $\mathrm{S}_{15}$, P1b/2a-b/3 and 4 all exhibited typical AIE features. The DMF solutions of $\mathrm{P} \mathbf{1 b} / \mathbf{2 a} / \mathbf{3}$ and $\mathrm{P} \mathbf{1 b} / \mathbf{2 b} / \mathbf{3}$ were weakly emissive with the maximum emission wavelength $\left(\lambda_{\mathrm{em}, \max }\right)$ at $507 \mathrm{~nm}$ and $516 \mathrm{~nm}$, respectively. As the water fraction $\left(f_{\mathrm{w}}\right)$ rose, the PL intensity of $\mathrm{P} \mathbf{1} \mathbf{b} / \mathbf{2} \mathbf{a}-\mathbf{b} / 3$ were first quickly enhanced and then kept almost unchanged. This tendency could be explained by the easy formation of polymer aggregates in DMF/water mixtures even at a low $f_{\mathrm{w}}$. By contrast, model compound 4 kept non-emissive before $f_{\mathrm{w}}$ reached $80 \%$. Once a large amount of water $\left(f_{\mathrm{w}}>\right.$ $80 \%$ ) was added into its DMF solution, this TPE-containing small molecule can be induced to form aggregates and show strong greenish-blue fluorescence $\left(\lambda_{\text {em, max }}=485 \mathrm{~nm}\right)$. Different from P1b/2a-b/3 and 4, the diethylamino-substituted P1e/2a/3 exhibited the strongest fluorescence intensity at a $f_{\mathrm{w}}$ of $20 \%$ (Figure $2 \mathrm{D}$ and $2 \mathrm{~F}$ ). The addition of higher water content led to an obvious decrease in PL intensity. This result might arise from the poorer water solubility and stronger inter-/intra-chain interactions of $\mathrm{P} \mathbf{1 e} / \mathbf{2 a} / \mathbf{3}$ than other polymers. The extensive formation of aggregates at high water contents could reduce the effective solute concentration and thus weaken the fluorescence. The $\lambda_{\text {em,max }}$ of P1e/2a/3 was red-shifted to about $575 \mathrm{~nm}$ due to its better intramolecular charge transfer than $\mathrm{P} \mathbf{1 b} / \mathbf{2 a}-\mathbf{b} / \mathbf{3}$.

The fluorescence intensity of $\mathrm{P} \mathbf{1 e} / \mathbf{2 a} / \mathbf{3}$ nanoaggregates was not as strong as those of $P \mathbf{1 b} / \mathbf{2 a}-\mathbf{b} / \mathbf{3}$. Considering the potential protonation capability of amino groups, ${ }^{[50]}$ we then tried to adjust the luminescence behavior of $\mathrm{P} \mathbf{1 e} / \mathbf{2 a} / \mathbf{3}$ under acidic condition. Indeed, the addition of acid had a significant impact on the luminescence properties of $\mathrm{P} \mathbf{1 e} / \mathbf{2 a} / \mathbf{3}$. As indicated in Figure $2 \mathrm{E}-\mathrm{F}$, the acidified P1e/2a/3 exhibited the highest fluorescence intensity at a $f_{\mathrm{w}}$ of $60 \%$ due to its improved solubility in water. After acidification, the PL intensity P1e/2a/3 was significantly enhanced both in solution and aggregate states. The acidified solution of $\mathrm{P} \mathbf{1 e} / \mathbf{2 a} / \mathbf{3}$ showed $\mathrm{a}$ 7.5-fold enhancement in PL intensity compared with that without acid. Meanwhile, a remarkable blue shift in $\lambda_{\text {em,max }}$ was observed after acidification. These preliminary results encouraged us to further explore the acid-base response of $\mathrm{P} \mathbf{1 e} / \mathbf{2 a} / \mathbf{3}$ in detail.
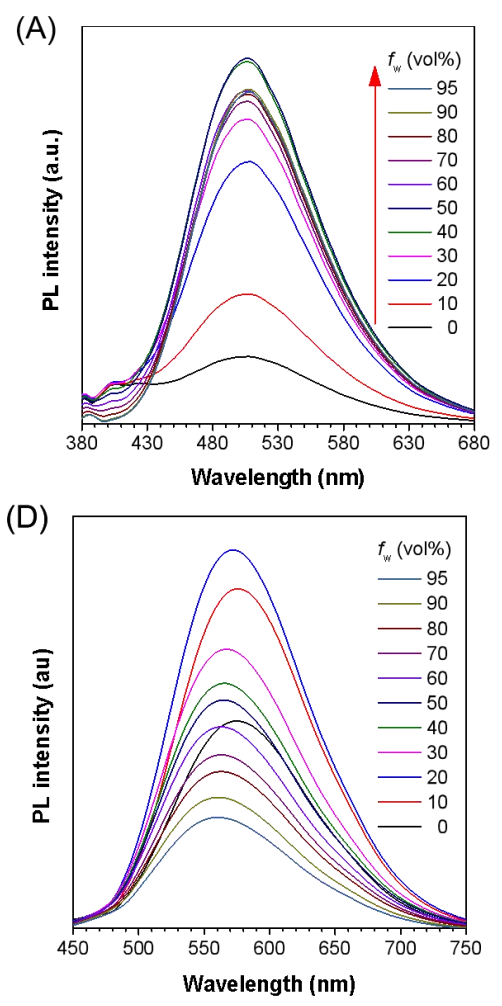

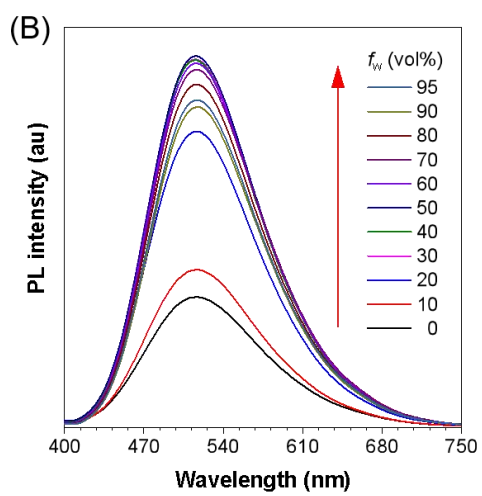

(E)

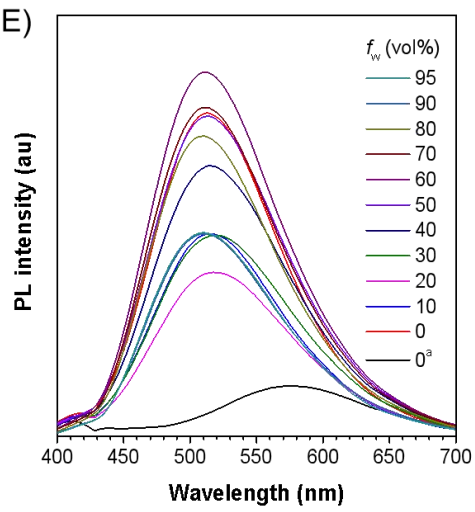

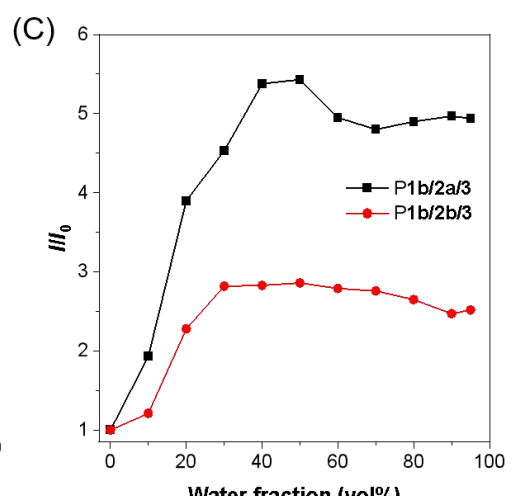

(F)

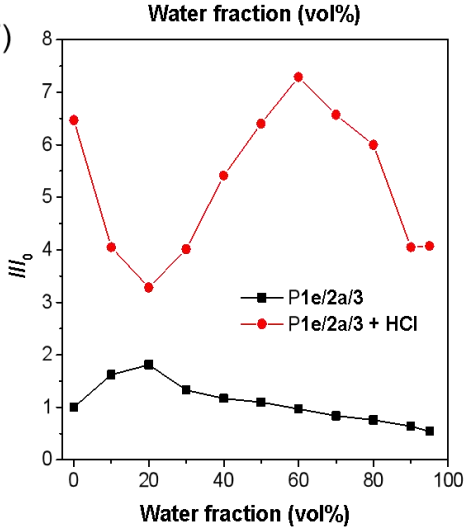

Figure 2. (A, B and D) Emission spectra of (A) P1b/2a/3, (B) P1b/2b/3 and (D) P1e/2a/3 in DMF/water mixtures with different water fractions $\left(f_{\mathrm{w}}\right)$. (E) Emission spectra of $\mathrm{P} \mathbf{1 e} / \mathbf{2 a} / \mathbf{3}$ in DMF/water mixtures with different $f_{\mathrm{w}}$ acidified with $10 \mathrm{mM}$ of hydrochloric acid. ( $C$ and F) Plot of relative PL intensity $\left(I / I_{\mathrm{o}}\right)$ versus the composition of the aqueous mixture of $(C)$ Pib/2a-b/3 
and (F) Pre/2a/3 and its acidified form. $I_{\mathrm{o}}=$ intensity at $f_{\mathrm{w}}=\mathrm{o} \%$. Solution concentration: $10 \mu \mathrm{M}$. Excitation wavelength $=(\mathrm{A}$ and B) $340 \mathrm{~nm},(\mathrm{D}) 400 \mathrm{~nm},(\mathrm{E}) 365 \mathrm{~nm} .{ }^{\text {a }}$ No acid was added.

\section{Acid-Base Response}

As presented in Figure S16, the fluorescence of the dilute DMF solution and nanoaggregates of P1e/2a/3 showed similar response to acid. That is, with the gradual addition of $\mathrm{HCl}$ aqueous solution, the PL intensity of P1e/2a/3 slightly decreased at first and then increased dramatically and the $\lambda_{\text {em,max }}$ obviously blue shifted. By contrast, the fluorescence behavior of the dimethylamino-containing AIE polymer (P1b/2a/3) changed little under acidic conditions (Figure $\mathrm{S} 17$ ). The insensitive fluorescence response of $\mathrm{P} \mathbf{1 b} / \mathbf{2 a} / \mathbf{3}$ could be ascribed to the poor electronic communication between the dimethylamino group and the TPE unit. By introducing amino groups in TPE moiety, the acid response behavior of AIE polymers could be greatly promoted.

We then tested the emission behavior of P1e/2a/3 under different precise $\mathrm{pH}$ conditions. As depicted in Figure $3 \mathrm{~A}$, when the $\mathrm{pH}$ value was steadily changed from 7.1 to 1.1, the fluorescence color of P1e/2a/3 nanoaggregates was gradually blue-shifted from orange-red $\left(\lambda_{\mathrm{em}, \max }=565 \mathrm{~nm}\right)$ to greenish-blue $\left(\lambda_{\mathrm{em}, \max }=\right.$ $503 \mathrm{~nm})$. At $\mathrm{pH}=2.1$, the fluorescence intensity of P1e/2a/3 was sharply enhanced to show a nearly light-up response. Therefore, the nanoaggregates of $\mathrm{P} \mathbf{1 e} / \mathbf{2 a} / \mathbf{3}$ are potential to be empolyed as a fluorescence sensor toward $\mathrm{pH}$ or acid-base conditions. To facilitate practical applications, a thin film of $\mathrm{P} \mathbf{e} / \mathbf{2 a} / 3$ was prepared by drop-coating its DMF solution on a quartz plate and its acid-base response behavior was examined. As shown in Figure $3 \mathrm{~B}$, the polymer thin film was fumed with $\mathrm{HCl}$ vapor for 1 min followed by fuming with $\mathrm{NH}_{3}$ vapor for 30 s. Similar to the responsive behavior of $\mathrm{P} \mathbf{1 e} / \mathbf{2 a} / \mathbf{3}$ nanoaggregates, both the absorption and emission maxima of the thin film were blue-shifted after exposure to $\mathrm{HCl}$ vapor. The maximum emission peak changed from 586 to $524 \mathrm{~nm}$ accompanied with a sharp increase of intensity. When the acid-fumed thin film was exposed to $\mathrm{NH}_{3}$ vapor, the fluorescence was quenched quickly and a red shift in absorption spectrum was observed.

In modern society, food safety is closely related to human health and its strict control has become increasingly important. The typical indicators for food spoilage were ammonia and biogenic amines generated from microbial growth. ${ }^{[5-53]}$ Based on the sensitive fluorescence response of the acid-treated P1e/2a/3 film toward $\mathrm{NH}_{3}$ vapor, we thus applied this thin film as a portable fluorescence sensor for detecting biological spoilage. As shown in Figure ${ }_{3} C$, fresh fish and the acid-treated thin film of P1e/2a/3 were sealed in a petri dish and placed at room temperature. Within the first $6 \mathrm{~h}$, the emission intensity of the film changed little. After $16 \mathrm{~h}$, there was a large drop in the PL intensity of the polymer film and the test film became almost non-emissive until $18 \mathrm{~h}$. At the same time, a darkened color change from pale yellow-green to light brown was also observed in the test film under normal room light. The above mentioned results demonstrated that $\mathrm{P} \mathbf{1 e} / \mathbf{2 a} / \mathbf{3}$ could be used as a dual-modal chemo-sensor for the sensitive detection of acid and amine vapors in real life scenario, in particular, for the effective detection of biogenic amines generated in food spoilage. 
(A)
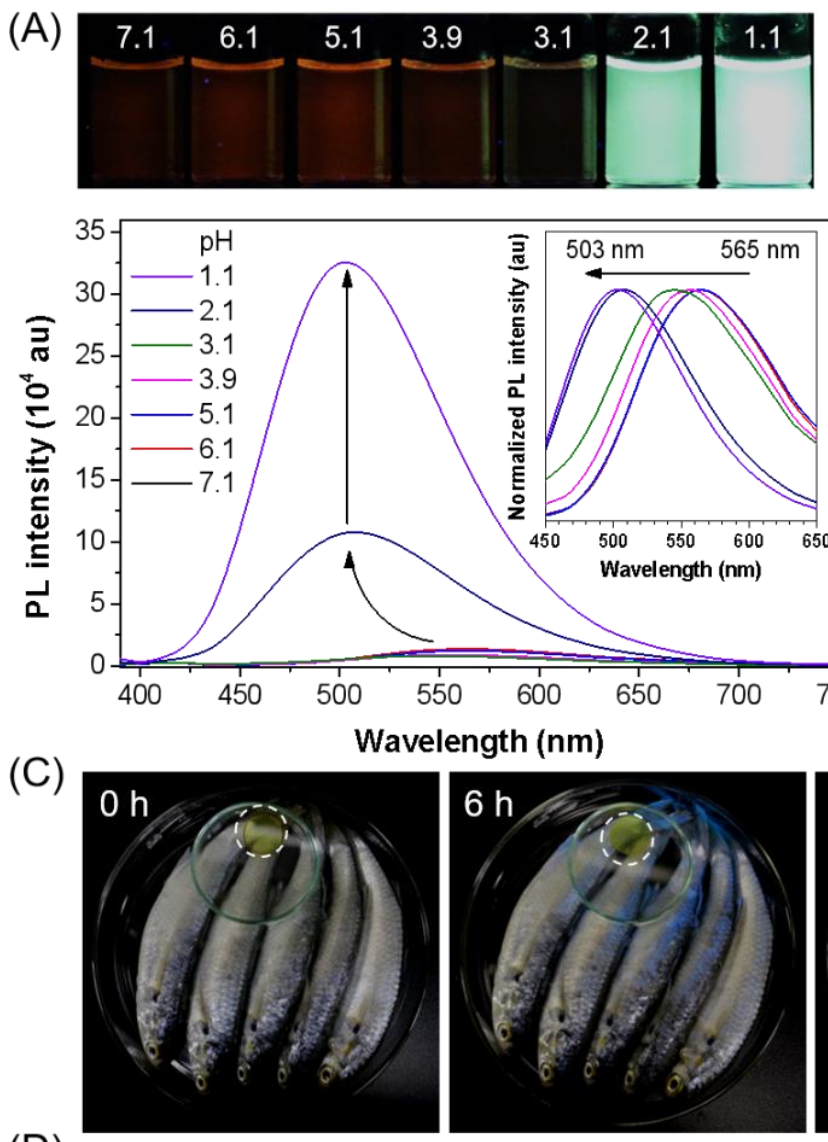

(D)
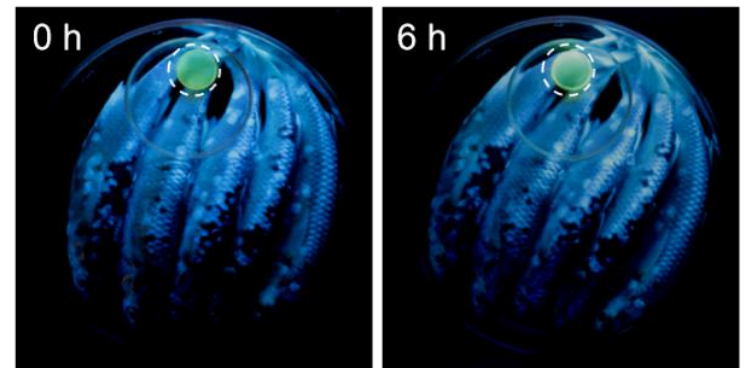

(B)
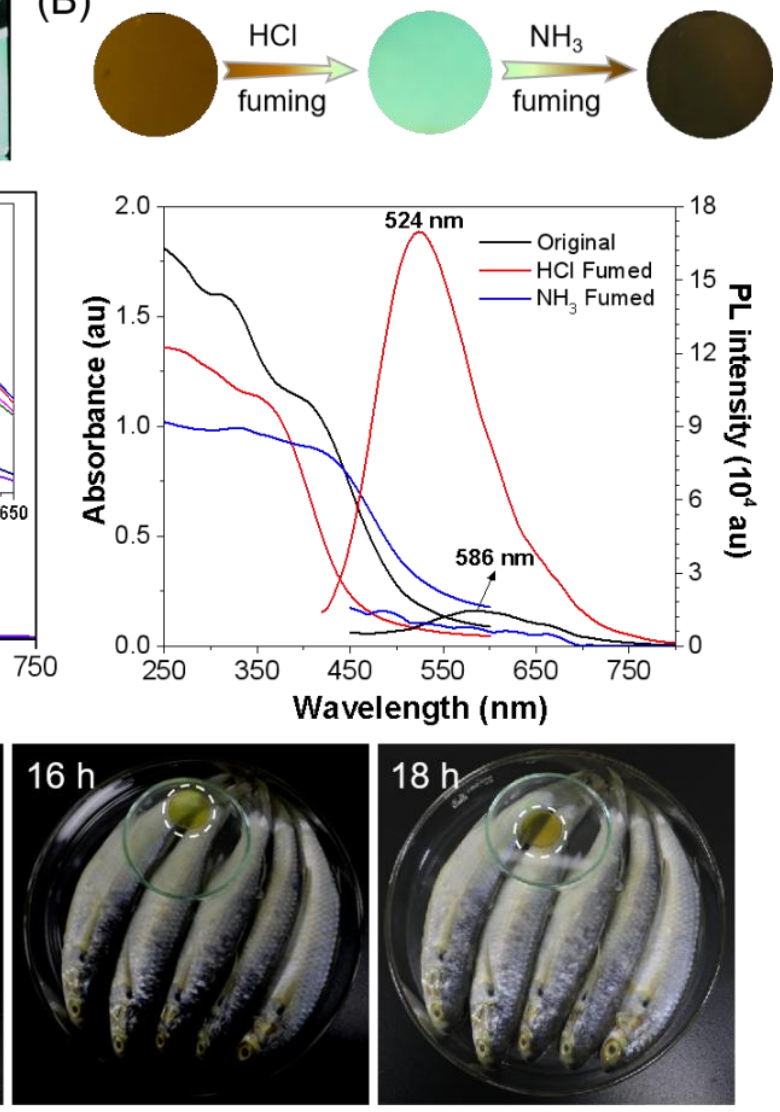

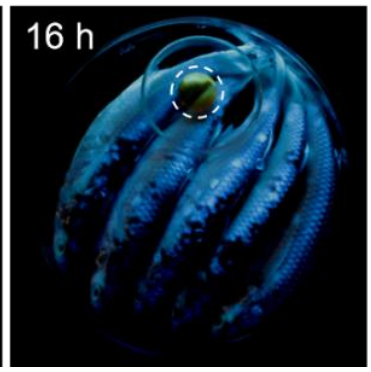

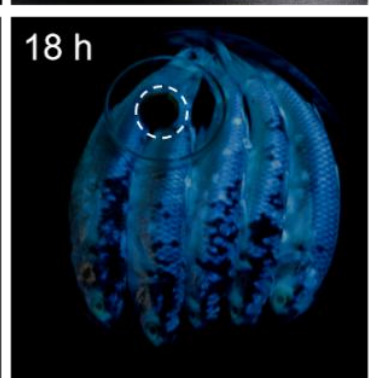

Figure 3. (A) Fluorescent photographs of P1e/2a/3 in $90 \% \mathrm{pH}$ buffer and 10\% DMF taken under $365 \mathrm{~nm}$ UV irradiation and the associated emission spectra. Polymer concentration: $10 \mu \mathrm{M}$. Excitation wavelength $=365 \mathrm{~nm}$. (B) Fluorescent photographs and the associated absorption and emission spectra of a thin film of P1e/2a/3 after fuming with $\mathrm{HCl}$ vapor for 1 min followed by fuming with $\mathrm{NH}_{3}$ vapor for $30 \mathrm{~s}$. The photographs were taken under $365 \mathrm{~nm}$ UV irradiation. (C and D) Photographs showing the spoilage detection of fish at room temperature using the $\mathrm{HCl}$-fumed thin film of $\mathrm{P} \mathbf{1 e} / \mathbf{2 a} / \mathbf{3}$. The photographs were taken under (C) normal room light illumination and (D) $365 \mathrm{~nm}$ UV irradiation.

\section{Metal Ion Detection and Gold Recovery}

Taking advantage of the efficient aggregate-state luminescence along with heteroatom-rich structures, we then examined the potential of the obtained AIE polymers as fluorescent chemosensors for metal ion detection. First, we studied the interaction between $\mathrm{P} \mathbf{1 b} / \mathbf{2 a} / \mathbf{3}$ and various metal ions using fluorescence spectroscopy. To the fluorescent nanoaggregates of $\mathrm{P} \mathbf{1 b} / \mathbf{2 a} / \mathbf{3}$ were added 16 different metal ions $(100 \mu \mathrm{M})$ including $\mathrm{Na}^{+}, \mathrm{K}^{+}, \mathrm{Mg}^{2+}$, $\mathrm{Ca}^{2+}, \mathrm{Al}^{3+}, \mathrm{Ag}+, \mathrm{Cu}^{2+}, \mathrm{Ru}^{3+}, \mathrm{Au}^{3+}, \mathrm{Co}^{2+}, \mathrm{Fe}^{2+}, \mathrm{Mn}^{2+}, \mathrm{Pb}^{2+}, \mathrm{Ir}^{3+}$, $\mathrm{Pd}^{2+}, \mathrm{Ni}^{2+}$, respectively. Among them, $\mathrm{Ru}^{3+}$ significantly quenched the fluorescence with a 14-fold decrease in PL intensity and $\mathrm{Pd}^{2+}$ resulted in a 3 -fold decrease (Figure S19). No significant fluorescence variation was observed with the addition of other metal ions, indicating the possible application of $\mathrm{P} \mathbf{1 b} / \mathbf{2 a} / \mathbf{3}$ nanoaggregates for selective $\mathrm{Ru}^{3+}$ detection. Different from $\mathrm{P} \mathbf{1 b} / \mathbf{2 a} / \mathbf{3}$, the strong fluorescence of the acidified Pre/2a/3 nanoaggregates was selectively quenched by $\mathrm{Au}^{3+}$ among various metal ions, even at low metal ion concentration of $10 \mu \mathrm{M}$ (Figure S19 and Figure $4 \mathrm{~A}$ ). When the concentration of $\mathrm{Au}^{3+}$ was gradually increased from o to 10 $\mu \mathrm{M}$, the PL intensity continuously declined without any change in the spectral profiles (Figure $4 \mathrm{~B}$ ). The Stern-Volmer plot of the relative emission intensity $\left(\mathrm{I}_{\mathrm{o}} / \mathrm{I}\right)$ versus $\left[\mathrm{Au}^{3+}\right]$ implied a amplification effect of the acidified Pre/2a/3 nanoaggregates toward $\mathrm{Au}^{3+}$ and the quenching constant was up to $1636,180 \mathrm{M}^{-1}$. The limit of 
detection (LOD) was calculated to be $81 \mathrm{nM}$ (Figure $4 \mathrm{C}$ ), indicating the excellent sensitivity of the acidified $\mathrm{P} \mathbf{1 e} / \mathbf{2 a} / 3$ nanoaggregates for $\mathrm{Au}^{3+}$ detection. These results suggested that the introduction of diethylamino pendants significantly affects the functionality of polymers. The slight structural difference between $\mathrm{P} \mathbf{1 b} / \mathbf{2 a} / \mathbf{3}$ and $\mathrm{P} \mathbf{1 e} / \mathbf{2 a} / \mathbf{3}$ led to distinct selectivity in metal ions.
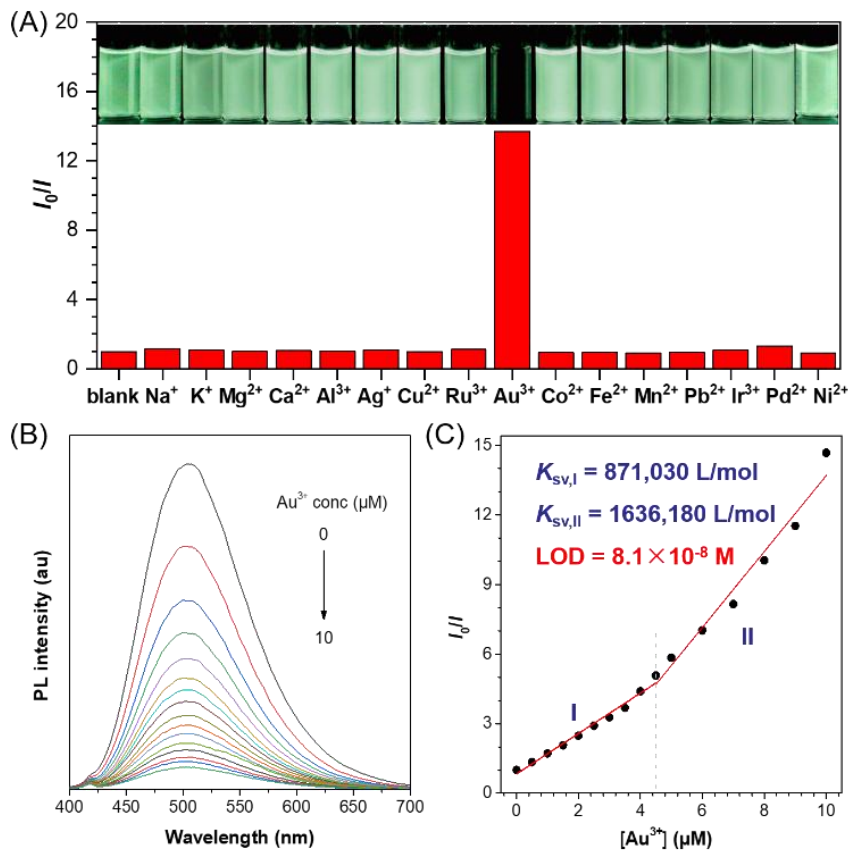

Figure 4. (A) Relative intensity $\left(I_{\mathrm{o}} / I\right)$ of P1e/2a/3 (10 $\left.\mu \mathrm{M}\right)$ in $10 \% \mathrm{DMF}$ and $90 \% \mathrm{pH}=1$ aqueous buffer mixtures containing different metal ions $(10 \mu \mathrm{M}) . I_{\mathrm{o}}=$ fluorescence intensity in the absence of metal cations. Inset: the corresponding fluorescent photographs taken under UV illumination. (B) Emission spectra of P1e/2a/3 in DMF/water mixtures (10 $\mu \mathrm{M})$ with $90 \% \mathrm{pH}=1$ aqueous buffer solution containing different concentrations of $\mathrm{Au}^{3+}$. Excitation wavelength $=365 \mathrm{~nm}$. (C) Stern-Volmer plot of relative intensity $\left(I_{\mathrm{o}} / I\right)$ of P1e/2a/3 (10 $\mu \mathrm{M})$ in $10 \%$ DMF and $90 \% \mathrm{pH}=1$ aqueous buffer mixtures versus $\left[\mathrm{Au}^{3+}\right]$

Gold is a valuable currency metal and is widely used in diverse fields. To meet the high annual demand for gold, a large part of gold is recycled from gold-containing industrial wastes such as the waste circuit boards.[54-55] Conventional methods for gold extraction usually suffered from the toxicity of inorganic cyanide and hypochlorite, extreme $\mathrm{pH}$ conditions, limited efficiency, and environmental problems. In recent few years, some green strategies have been developed for effective gold enrichment, such as based on the strong coordination of $\mathrm{Au}^{3+}$ with sulfur or selenium in hydrophobic polymers, ${ }^{[56-57]}$ or complexation with nitrogen atoms especially those involved in metal-organic framework (MOF) materials, ${ }^{\left[{ }^{8}\right]}$ as well as the bacteria-enrichment method. [59] Encouraged by the highly selective and sensitive detection of $\mathrm{Au}^{3+}$ by $\mathrm{P} \mathbf{1 e} / \mathbf{2 a} / \mathbf{3}$, we envisioned that this nitrogen-rich polymer might also be useful for gold enrichment.
As shown in Figure $5 \mathrm{~A}$, when the DMF solution of $\mathrm{P} \mathbf{e} / \mathbf{2 a} / 3$ was added into the $\mathrm{Au}^{3+}$ solution, brown precipitate appeared immediately probably due to the poor solubility of the formed polymer-Au ${ }^{3+}$ complex. Inspired by the preliminary result, we then conducted more detailed experiments on the gold enrichment capability of Pre/2a/3. Firstly, into the aqueous solution of $\mathrm{Au}^{3+}(100 \mathrm{mg} / \mathrm{L})$ was added different amount of $\mathrm{P} \mathbf{e} / \mathbf{2 a} / \mathbf{3}$ powder. The mixture was allowed to stir at room temperature for $\mathrm{hh}$. After centrifugation, the remaining metal ion concentration in the supernatant was examined by inductively coupled plasma-optical emission spectroscopy (ICP-OES) to calculate the enrichment efficiency. As the dosage of $\mathrm{Pre} / \mathbf{2 a} / \mathbf{3}$ powder increased, the enrichment efficiency gradually rose and could reach $98.9 \%$ in the presence of $4 \mathrm{mg} \mathrm{P1e/2a/3}$ (Figure $5 \mathrm{~A}$, red line). The maximal extraction capacity was calculated to be $274 \mathrm{mg} \cdot \mathrm{Au}^{3+} / \mathrm{g}$. The speed of this gold enrichment process was then tested. As indicated by the blue line in Figure $5 \mathrm{~A}$, a high enrichment efficiency of over $96 \%$ was achieved within $5 \mathrm{~min}$ using $4 \mathrm{mg} \mathrm{P} \mathbf{e} / \mathbf{2 a} / \mathbf{3}$ and the mixture reached equilibrium after 30 min with $>98 \%$ enrichment efficiency. These results suggested that P1e/2a/3 possessed excellent gold enrichment capability. By comparison, the $\mathrm{Au}^{3+}$ extraction efficiency of polymer $\mathrm{P} \mathbf{1 b} / \mathbf{2 a} / \mathbf{3}$ was much lower (29\%), which implied that the diethylamino substituent in Pre/2a/3 could strengthen its coordination ability with gold ion.

To explore the enrichment selectivity of P1e/2a/3 among different metal ions, the solid polymer powder was added into the respective aqueous solutions of $\mathrm{Mn}^{2+}, \mathrm{Cu}^{2+}$, $\mathrm{Co} 2+, \mathrm{Ni}^{2+}, \mathrm{Cd}^{2+}, \mathrm{Pd}^{2+}, \mathrm{Ru}^{3+}, \mathrm{Na}^{+}, \mathrm{Ca}^{2+}, \mathrm{Mg}^{2+}$, and $\mathrm{Au}^{3+}$. As shown in Figure S20, the highest enrichment efficiency was realized for $\mathrm{Au}^{3+}(>99 \%)$ although $\mathrm{Cd}^{2+}$ and $\mathrm{Pd}^{2+}$ also had weak interaction with the polymer. In the mixed solution of the 11 different metal ions, Pre/2a/3 can still selectively enrich $\mathrm{Au}^{3+}$ with a high efficiency of $97.53 \%$ (Figure ${ }_{5} \mathrm{~B}$ ). The extraction efficiency of $\mathrm{P} \mathbf{e} / \mathbf{2 a} / 3$ for $\mathrm{Pd}^{2+}$ and $\mathrm{Cd}^{2+}$ in the metal ion mixture was $29.32 \%$ and $2.01 \%$, respectively, while the efficiency for other metal ions was below $\mathbf{1 . 2 1} \%$. Therefore, P1e/2a/3 is promising to extract $\mathrm{Au}^{3+}$ rapidly and selectively with a high efficiency under practical conditions. Furthermore, elemental gold can be recycled by facile pyrolysis of the obtained $\mathrm{P} \mathbf{1} / \mathbf{2 a} / \mathbf{3}^{-} \mathrm{Au}^{3^{+}}$ complex. As depicted in Figure ${ }_{5} \mathrm{C}$, a yellow solid with metallic golden luster was obtained as residue after heating the dark complex at $1000{ }^{\circ} \mathrm{C}$ in air for $4 \mathrm{~h}$. The gold content in this yellow solid was measured to be 96.61 wt $\%$ by ICP-OES.

To elucidate the coordination mechanism of the heteroatom-rich polymer with $\mathrm{Au}^{3+}$, we measured the XPS spectra of $\mathrm{P} \mathbf{1 e} / \mathbf{2 a} / \mathbf{3}$ and $\mathrm{P} \mathbf{1 b} / \mathbf{2 a} / \mathbf{3}$ before and after coordination with $\mathrm{Au}^{3+}$. The XPS spectrum of S $2 \mathrm{p}$ and $\mathrm{N}$ is of $\mathrm{P} \mathbf{1 b} / \mathbf{2 a} / \mathbf{3}$ showed slight difference before and after coordination, and no change was observed in its $\mathrm{O}$ is spectrum (Figure S21). This result indicated that the $\mathrm{N}$ and $\mathrm{S}$ atoms in polymer backbones might have weak interactions with $\mathrm{Au}^{3+}$. The change in $\mathrm{O}$ is and $\mathrm{S} 2 \mathrm{p}$ region of the XPS spectrum of Pre/2a/3 was similar to that of 
P1b/2a/3 (Figure $5 \mathrm{D}-\mathrm{E}$ and Figure S22A-B). By contrast, the spectrum profile in the $\mathrm{N}$ is region of $\mathrm{P} \mathbf{e} / \mathbf{2 a} / \mathbf{3}$ changed significantly after coordination with $\mathrm{Au}^{3+}$ (Figure ${ }_{5} \mathrm{~F}$ and Figure $\mathrm{S}_{22} \mathrm{C}$ ). The original two peaks at 400.98 and $397.98 \mathrm{eV}$ split into three peaks at $401.58,399.78$ and $398.08 \mathrm{eV}$ in the $\mathrm{N}$ is spectrum of Pre/2a/3- $\mathrm{Au}^{3+}$. These

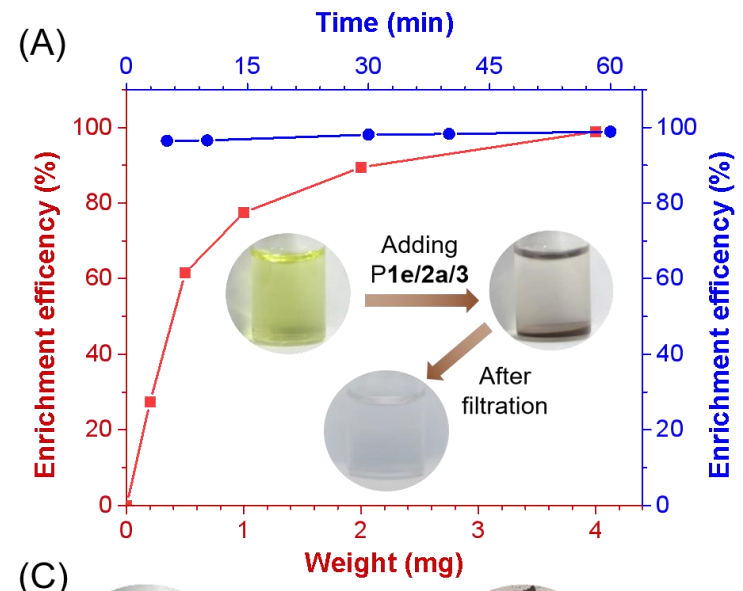

(C)

results further demonstrated that the $\mathrm{N}$ atoms of the diethylamino groups have a great contribution to the strong coordination of $\mathrm{P} \mathbf{e} / \mathbf{2 a} / \mathbf{3}$ with $\mathrm{Au}^{3+}$, while the $\mathrm{N}$ atoms in dimethylamino groups and $\mathrm{S}$ atoms are relatively less involved in the coordination process.

(B)

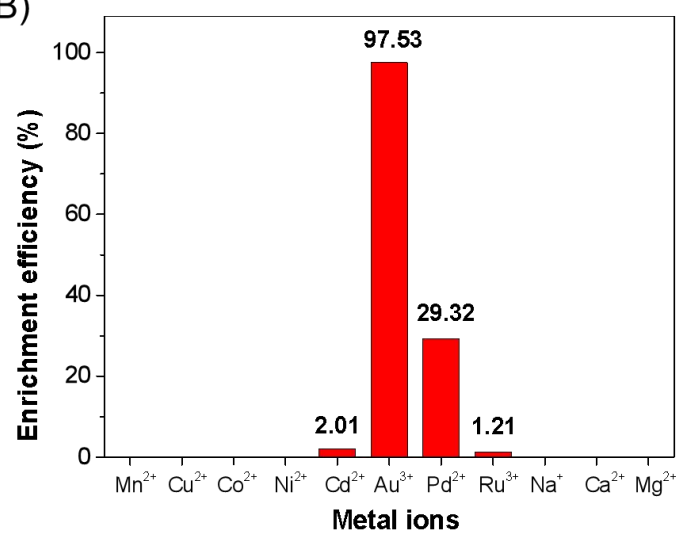

(E)

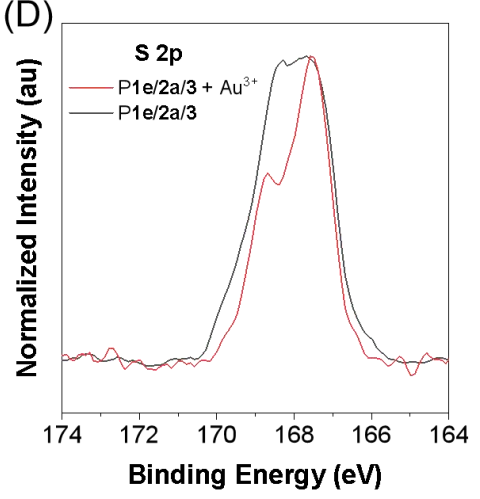

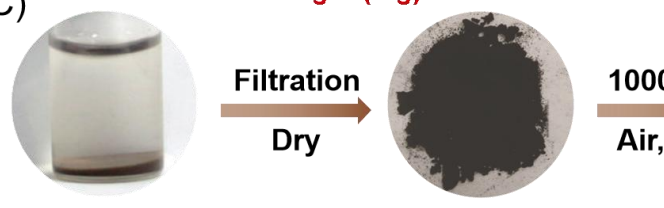

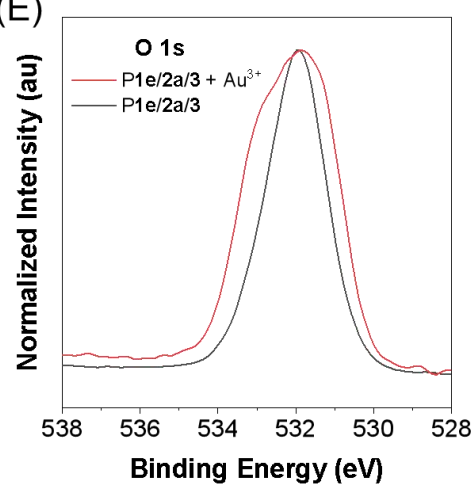

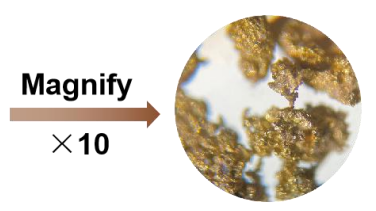

(F)

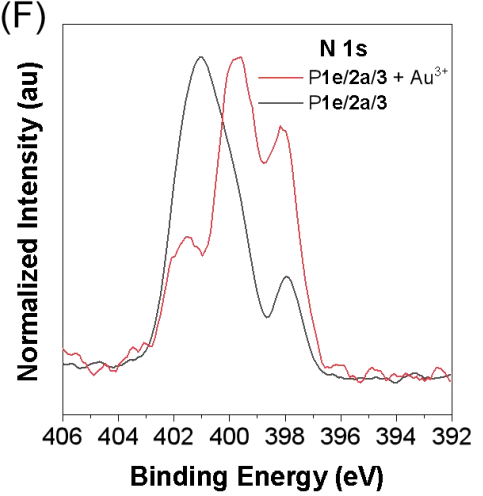

Figure 5. (A) Enrichment efficiency of $\mathrm{Au}^{3+}$ with different amounts of Pre/2a/3 powder (red line) and the time-dependent extraction of $\mathrm{Au}^{3+}$ with $4 \mathrm{mg} \mathrm{P1e} / \mathbf{2 a} / 3$ powder (blue line). Inset: the gold extraction process with $\mathrm{Pre} / \mathbf{2 a} / \mathbf{3}$. $\left[\mathrm{Au}^{3+}\right]_{\mathrm{o}}=100 \mathrm{mg} / \mathrm{L}$, $\mathrm{V}_{\mathrm{Au}^{3+}}=2 \mathrm{~mL}$. (B) Selective extraction of $\mathrm{Au}^{3+}$ using the solid powder of Pre/2a/3 in an aqueous solution with $11 \mathrm{mixed}$ metal ions. $\left[\mathrm{M}^{\mathrm{n}+}\right]_{\mathrm{o}}=100 \mathrm{mg} / \mathrm{L}, \mathrm{V}_{\mathrm{M}^{\mathrm{n}+}}=2 \mathrm{~mL}, \mathrm{~m}_{\mathrm{P} \mathbf{e} / 2 \mathrm{a} / 3}=4 \mathrm{mg}$. (C) The process of gold recovery from an aqueous solution to elemental Au using P1e/2a/3. The magnified image was observed under a microscope. (D) XPS spectra for $\mathrm{N}$ 1s, O 1s, $\mathrm{S} 2 \mathrm{p}$ of P1e/2a/3 and

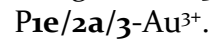

\section{Cell Imaging}

Inspired by the special biological activities of amidine derivatives and the advantages of AIE luminogens as fluorescence imaging reagents, ${ }^{[10-14},{ }^{60]}$ we then investigated the applications of the obtained AIE-active amidine-containing polymers in biological imaging. The staining capability of Plb/2a/3 on different type of cells was first investigated as an example using a confocal laser scanning microscope. As shown in Figure 6A-B and Figure S23, bright blue fluorescence was observed in both $4 \mathrm{~T} 1$ and $3^{\mathrm{T}} 3$ cells after incubation with $10 \mu \mathrm{M}$ polymer for $2 \mathrm{~h}$. The co-staining results of P1b/2a/3 with LysoTracker Red (LTR, a commercial lysosome-imaging probe) revealed that $\mathrm{P} \mathbf{b} / \mathbf{2 a} / \mathbf{3}$ can specifically localize and stain lysosomes in the tested cells. The cell staining regions of $\mathrm{P} \mathbf{1 b} / \mathbf{2} \mathbf{a} / \mathbf{3}$ overlapped well with those of LTR. The Pearson's correlation coefficient of $\mathrm{P} \mathbf{1 b} / \mathbf{2 a} / \mathbf{3}$ for $4^{\mathrm{T}} 1$ and $3 \mathrm{~T}_{3}$ cells was calculated to be 0.84 and 0.87 , respectively. The cytotoxicities of $\mathrm{P} \mathbf{1 b} / \mathbf{2 a} / \mathbf{3}$ to $4 \mathrm{~T}_{1}$ and $3 \mathrm{~T}_{3}$ cells were evaluated using a standard MTT cell viability assay (Figure $6 \mathrm{C}$ ). The cell viability of $4 \mathrm{~T}_{1}$ and $3 \mathrm{~T}_{3}$ cells both remained above $90 \%$ even at a high concentration of up to $80 \mu \mathrm{M}$, indicating the excellent biocompatibility of $\mathrm{P} \mathbf{1 b} / \mathbf{2 a} / \mathbf{3}$. Furthermore, this AIE polymer showed prominent photobleaching resistance. No remarkable signal loss occurred after 50 scans with continuous irradiation at $405 \mathrm{~nm}$ excitation, while more than $40 \%$ of the fluorescence of LysoTracker Green was lost (Figure 
6D). The low cytotoxicity, high lysosome specificity, and excellent photostability make $\mathrm{P} \mathbf{1 b} / \mathbf{2 a} / \mathbf{3}$ a promising lysosome-specific fluorescent probe in biological imaging.
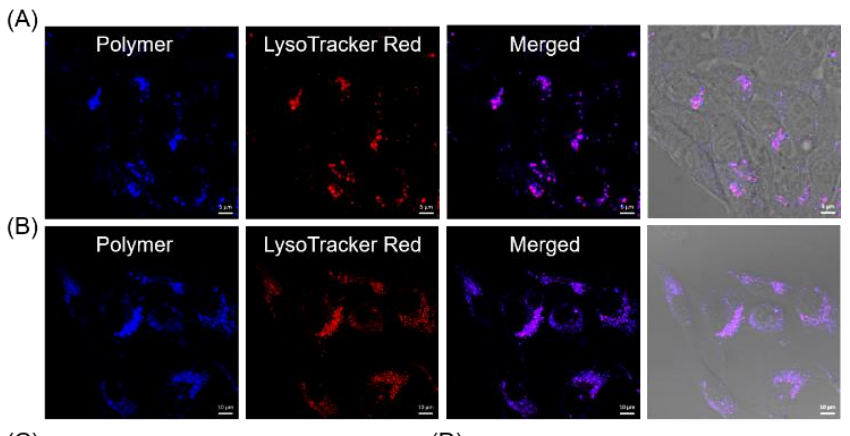

(C)

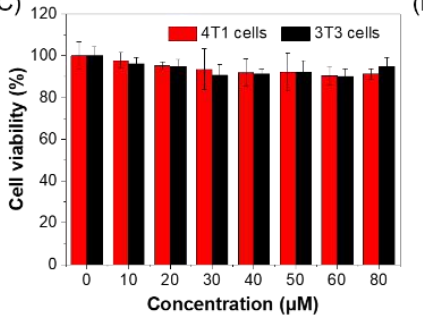

(D) 120

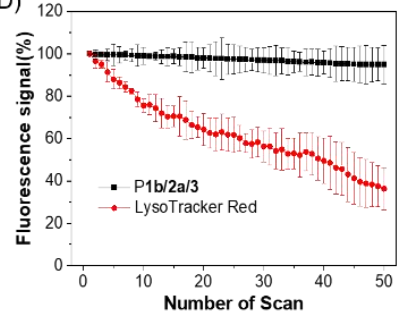

Figure 6. (A and B) Confocal images of (A) 4 Ti cells and (B) 3T3 cells stained with Prb/2a/3 (10 $\mu \mathrm{M}, 2 \mathrm{~h}$ ) and LysoTracker Red (LTR, $1 \mu \mathrm{M}, 30 \mathrm{~min}$ ) and their merged images as well as the overlay of the fluorescence image and bright-field image. Scale bar $=5 \mu \mathrm{M}$ (for $4 \mathrm{~T} 1$ cells) and $10 \mu \mathrm{M}$ (for $3 \mathrm{~T}_{3}$ cells). Excitation wavelength: $405 \mathrm{~nm}(\mathrm{Plb} / \mathbf{2 a} / 3)$ and $514 \mathrm{~nm}$ (LTR); emission filter: $450-650 \mathrm{~nm}(\mathrm{P} \mathbf{l b} / \mathbf{2 a} / 3)$ and $550-735 \mathrm{~nm}$ (LTR). (C) Cell viability of $4 \mathrm{~T} 1$ and $3 \mathrm{~T}_{3}$ cells in the presence of $\mathrm{Plb} / \mathbf{2 a} / \mathbf{3}$ at different concentrations. (D) Change in the fluorescence signal from 4T1 cells stained with Prb/2a/3 (10 $\mu \mathrm{M}, 2 \mathrm{~h})$ and LTR ( $1 \mu \mathrm{M}, 30 \mathrm{~min})$.

\section{CONCLUSIONS}

In summary, we have developed a straightforward and powerful tool for the synthesis of diverse heterochain polymers with $\alpha, \beta$-unsaturated amidines. This synthetic method enjoys the merits of readily accessible monomers, facile operation, high efficiency, mild condition and high atom economy. The isolated yield was up to $91 \%$ and the $M_{\mathrm{w}}$ of the obtained polymers could reach up to 74500 . All the obtained polymers are formed with excellent stereoselectivity and possess good solubility in common polar solvents. In the presence of AIE unit and diethylamino substitutents, Pre/2a/3 showed acid-base dual modal response and the acidified thin film can be used as a sensitive fluorescence probe for detecting biological spoilage. Meanwhile, the heteroatom-rich Pre/2a/3 can also be utilized for the highly sensitive and selective detection of $\mathrm{Au}^{3+}$ and furthermore can rapidly enrich $\mathrm{Au}^{3+}$ from aqueous solution with a high efficiency. The XPS experiment data indicated the $\mathrm{N}$ atoms of the diethylamino group greatly promoted the extraction efficiency of P1e/2a/3 toward $\mathrm{Au}^{3+}$. Besides P1e/2a/3, the AIE-active P1b/2a/3 was demonstrated to be a promising lysosome-specific fluorescent probe with low cytotoxicity, high specificity, and prominent photostability. Further experiments on the more practical applications of these heterochain polymers, such as the combination of their gold enrichment capability and the desalination of sea water, were undergoing in our lab.

\section{ASSOCIATED CONTENT}

Supporting Information. Details of the materials, methods, synthetic procedures, and characterization data (IR, NMR, TGA, DSC, etc.); effect of solvent on the polymerization; photophysical properties of the model compound and polymers; metal ion detection, gold enrichment, and cell imaging data. This material is available free of charge via the Internet at http://pubs.acs.org.

\section{AUTHOR INFORMATION}

\section{Corresponding Author}

*hanting@szu.edu.cn

*wangd@szu.edu.cn

*tangbenz@cuhk.edu.cn

\section{Notes}

The authors declare no competing financial interest.

\section{ACKNOWLEDGMENT}

This work was supported by the National Natural Science Foundation of China (grant numbers 21905176, 21801169), the Natural Science Foundation for Distinguished Young Scholars of Guangdong Province (grant number 2020B1515020011), and the Science and Technology Plan of Shenzhen (grant number JCYJ20190808142403590, JCYJ20190808153415062). The authors also acknowledge the Instrumental Analysis Center of Shenzhen University.

\section{REFERENCES}

(1) Jeffrey, G. A.; Saenger, W. Hydrogen Bonding in Biological Structures. Springer-Verlag, Berlin 1991.

(2) Jeffrey, G.; Maluszynska, H.; Mitra, J. Hydrogen bonding in nucleosides and nucleotides. Int. J. Biol. Macromol. 1985, 7, 336.

(3) Grabowski, S. J. Hydrogen Bonding: New Insights, Vol. 3, Springer, New York 2006.

(4) Frey, P. A.; Hegeman, A. D. Enzymatic Reaction Mechanisms. Oxford University Press, Oxford 2007.

(5) Gunes, S.; Neugebauer, H.; Sariciftci, N. S. Conjugated Polymer-Based Organic Solar Cells. Chem. Rev. 2007, 107, 1324.

(6) Gribble, G. W.; Joule, J. A. Progress in Heterocyclic Chemistry. Elsevier: Oxford, 2016.

(7) Liu, Y. J.; Lam, J. W. Y.; Tang, B. Z. Conjugated polymers developed from alkynes. Natl. Sci. Rev. 2o15, 2, 493.

(8) Lu, L. Y.; Chen, W.; Xu, T.; Yu, L. P. High-performance ternary blend polymer solar cells involving both energy transfer and hole relay processes. Nat. Commun. 2015, 6, 7327.

(9) Yang, G. M.; Liu, L. B.; Yang, Q.; Lv, F. T.; Wang, S. A Multifunctional Cationic Pentathiophene: Synthesis, Organelle-Selective Imaging, and Anticancer Activity. Adv. Funct. Mater. 2012, 22, 736. 
(10) Song, Z. L.; Chen, H. L.; Wang, Y. H.; Goto, M.; Gao, W. J.; Cheng, P. L.; Morris-Natschke, S. L.; Liu, Y. Q.; Zhu, G. X.; Wang, M. J.; Lee, K. H. Design and synthesis of novel PEG-conjugated $20(S)$-camptothecin sulfonylamidine derivatives with potent in vitro antitumor activity via Cu-catalyzed three-component reaction. Bioorg. Med. Chem. Lett. 2015, 25, 2690.

(11) Wang, M.-J.; Liu, Y.-Q.; Chang, L. C.; Wang, C.-Y.; Zhao, Y.-L.; Zhao, X.-B.; Qian, K.; Nan, X.; Yang, L.; Yang, X.-M.; Hung, H.-Y.; Yang, J.-S.; Kuo, D.-H.; Goto, M.; Morris-Natschke, S. L.; Pan, S.-L.; Teng, C.-M.; Kuo, S.-C.; Wu, T.-S.; Wu, Y.-C.; Lee, K.-H. Design, Synthesis, Mechanisms of Action, and Toxicity of Novel 20(S)-Sulfonylamidine Derivatives of Camptothecin as Potent Antitumor Agents. J. Med. Chem. 2014, 57, 6008.

(12) Lee, M. Y.; Kim, M. H.; Kim, J.; Kim, S. H.; Kim, B. T.; Jeong, I. H.; Chang, S.; Kim S. H.; Chang, S. Synthesis and SAR of sulfonyl- and phosphoryl amidine compounds as anti-resorptive agents. Bioorg. Med. Chem. Lett. 2010, 20, 541.

(13) Chang, S.-Y.; Bae, S. J.; Lee, M. Y.; Baek, S.-H.; Chang, S.; Kim, S. H. Chemical affinity matrix-based identification of prohibitin as a binding protein to anti-resorptive sulfonyl amidine compounds. Bioorg. Med. Chem. Lett. 2011, 21, 727.

(14) Suja, T. D.; Divya, K. V.; Naik, L. V.; Ravi Kumar, A.; Kamal, A. Copper-catalyzed three-component synthesis of aminonaphthoquinone-sulfonylamidine conjugates and in vitro evaluation of their antiproliferative activity. Bioorg. Med. Chem. Lett. 2016, 26, 2072.

(15) Kim, M.; Park, J.-W. Reversible, solid state capture of carbon dioxide by hydroxylated amidines. Chem. Commun. 2010, 46, 2507.

(16) Endo, T.; Nagai, D.; Monma, T.; Yamaguchi, H.; Ochiai, B. A novel construction of a reversible fixation-release system of carbon dioxide by amidines and their polymers. Macromolecules 2004, 37, 2007.

(17) Rotstein, B. H.; Zaretsky, S.; Rai, V.; Yudin, A. K. Small Heterocycles in Multicomponent Reactions. Chem. Rev. 2014, 114, 8323.

(18) Estevez, V.; Villacampa, M.; Menendez, J. C. Recent Advances in the Synthesis of Pyrroles by Multicomponent Reactions. Chem. Soc. Rev. 2014, 43, 4633.

(19) Alvim, H. G. O.; da Silva, E. N.; Neto, B. A. D. What Do We Know About Multicomponent Reactions? Mechanisms and Trends for the Biginelli, Hantzsch, Mannich, Passerini and Ugi MCRs. RSC Adv. 2014, 4, 54282.

(20) Domling, A.; Wang, W.; Wang, K. Chemistry and Biology of Multicomponent Reactions. Chem. Rev. 2012, 112, 3083.

(21) Long, Z.; Mao, L. C.; Liu, M. Y.; Wan, Q.; Wan, Y. Q.; Zhang, X. Y.; Wei, Y. Marrying multicomponent reactions and aggregation-induced emission (AIE): new directions for fluorescent nanoprobes. Polym. Chem. 2o17, 8, 5644.

(22) Hu, R.; Li, W.; Tang, B. Z. Recent Advances in Alkyne-Based Multicomponent Polymerizations. Macromol. Chem. Phys. 2016, 217, 213.

(23) Ochiai, B.; Ogihara, T.; Mashiko, M.; Endo, T. Synthesis of Rare-metal Absorbing Polymer by Three-component Polyaddition through Combination of Chemo-selective Nucleophilic and Radical Additions. J. Am. Chem. Soc. 2oog, 131, 1636.

(24) Espeel, P.; Goethals, F.; Du Prez, F. E. One-pot multistepr Reactions based on thiolactones: extending the realm of thiol-ene chemistry in polymer synthesis. J. Am. Chem. Soc. 2011, 133,1678 .

(25) Estevez, V.; Villacampa, M.; Menendez, J. C. Recent Advances in the Synthesis of Pyrroles by Multicomponent Reactions. Chem. Soc. Rev. 2014, 43, 4633

(26) Blasco, E.; Sims, M. B.; Goldmann, A. S.; Sumerlin, B. S.; Barner-Kowollik, C. 5oth Anniversary Perspective: Polymer Functionalization. Macromolecules 2017, 50, 5215.
(27) Yang, B.; Zhao, Y.; Fu, C.; Zhu, Ch.; Zhang, Y.; Wang, S.; Wei, Y.; Tao, L. Introducing the Ugi reaction into polymer chemistry as a green click reaction to prepare middle-functional block copolymers. Polym. Chem. 2014, 5, 2704.

(28) Sehlinger, A.; Dannecker, P.-K.; Kreye, O.; Meier, M. A. R. Diversely Substituted Polyamides: Macromolecular Design Using the Ugi Four-Component Reaction. Macromolecules 2014, 47, 2774 .

(29) Kayser, L. V.; Hartigan, E. M.; Arndtsen, B. A. Multicomponent Coupling Approach to Cross-Conjugated Polymers from Vanillin-Based Monomers. ACS Sustainable Chem. Eng. 2016, 4, 6263.

(30) Dong, L.; Fu, W.; Liu, P.; Shi, J.; Tong, B.; Cai, Z.; Zhi, J.; Dong, Y. Spontaneous Multicomponent Polymerization of Imidazole, Diacetylenic Esters, and Diisocyanates for the Preparation of Poly( $\beta$-aminoacrylate)s with Cluster-Induced Emission Characteristics. Macromolecules 2020, 53, 1054.

(31) P. Liu, W. Fu, P. Verwilst, M. Won, J. Shin, Z. Cai, B. Tong, J. Shi, Y. Dong, J. S. Kim, MDM2-Associated Clusterization-Triggered Emission and Apoptosis Induction Effectuated by a Theranostic Spiropolymer. Angew. Chem., Int. Ed. 2020, 59, 8435 .

(32) Deng, H. Q.; Zhao, E. G.; Li, H. K.; Lam, J. W. Y.; Tang, B. Z. Multifunctional Poly( $N$-sulfonylamidine)s Constructed by $\mathrm{Cu}$-Catalyzed Three-Component Polycouplings of Diynes, Disulfonyl Azide, and Amino Esters. Macromolecules 2015, 48, 3180.

(33) Lee, I. H.; Kim, H.; Choi, T. L. Cu-Catalyzed Multicomponent Polymerization to Synthesize a Library of Poly(N-sulfonylamidines). J. Am. Chem. Soc. 2013, 135, 3760.

(34) Kim, H.; Bang, K. T.; Choi, I.; Lee, J. K.; Choi, T. L. Diversity-Oriented Polymerization: One-Shot Synthesis of Library of Graft and Dendronized Polymers by $\mathrm{Cu}$-Catalyzed Multicomponent Polymerization. J. Am. Chem. Soc. 2016, 138, 8612.

(35) Han, T.; Deng, H.; Qiu, Z.; Zhao, Z.; Zhang, H.; Zou, H.; Leung, N. L. C.; Shan, G.; Elsegood, M. R. J.; Lam, J. W. Y.; Tang, B. Z. Facile Multicomponent Polymerizations toward Unconventional Luminescent Polymers with Readily Openable Small Heterocycles. J. Am. Chem. Soc. 2018, 140, 5588.

(36) Xu, L.; Hu, R.; Tang, B. Z. Room Temperature Multicomponent Polymerizations of Alkynes, Sulfonyl Azides, and Iminophosphorane toward Heteroatom-Rich Multifunctional Poly-(phosphorus amidine)s. Macromolecules 2017, 50, 6043.

(37) Deng, H.; Han, T.; Zhao, E.; Kwok, R. T. K.; Lam, J. W. Y.; Tang, B. Z. Multicomponent Click Polymerization: A Facile Strategy toward Fused Heterocyclic Polymers. Macromolecules 2016, 49, 5475 .

(38) Xu, L.; Zhou, F.; Liao, M.; Hu, R.; Tang, B. Z. Room Temperature Multicomponent Polymerizations of Alkynes, Sulfonyl Azides, and $N$-Protected Isatins toward Oxindole-Containing Poly( $N$-acylsulfonamide)s. Polym. Chem. 2018, 9, 1674 .

(39) Deng, H. Q.; Han, T.; Zhao, E. G.; Kwok, R. T. K.; Lam, J. W. Y.; Tang, B. Z. Multicomponent polymerization: development of a one-pot synthetic route to functional polymers using diyne, $\mathrm{N}$-sulfonyl azide and water/ethanol as reactants. Polym. Chem. 2016, 7, 5646.

(40) Yao, B.; Shen, C.; Liang, Z.; Zhang, Y. Copper-Catalyzed Reaction of Ketenimine and in Situ Generated Immonium Ion: Access to $\alpha, \beta$-Unsaturated Amidines. J. Org. Chem. 2014, 79, 936.

(41) Yao, B.; Zhang, Y.; Li, Y. Copper-Catalyzed Coupling Reaction of C-OMe Bonds Adjacent to a Nitrogen Atom with Terminal Alkynes. J. Org. Chem. 2010, 75, 4554. 
(42) Luo, J. D.; Xie, Z. L.; Lam, J. W. Y.; Cheng, L.; Chen, H. Y.; Qiu, C. F.; Kwok, H. S.; Zhan, X. W.; Liu, Y. Q.; Zhu, D. B.; Tang, B. Z. Aggregation-induced emission of 1-methyl-1,2,3,4,5-pentaphenylsilole. Chem. Commun. 2oo1, 1740.

(43) Alam, P.; Leung, N. L.C.; Zhang, J.; Kwok, R. T.K.; Lam, J. W.Y., Tang, B. Z. AIE-based luminescence probes for metal ion detection. Coordination Chemistry Reviews 2021, 429, 213693.

(44) Xu, S.; Duan, Y.; Liu, B. Precise Molecular Design for High-Performance Luminogens with Aggregation-Induced Emission. Adv. Mater. 2020, 32, 1903530.

(45) Zhang, H.; Zhao, Z.; Turley, A. T.; Wang, L.; McGonigal, P. R.; Tu, Y.; Li, Y.; Wang, Z.; Kwok, R. T. K.; Lam, J. W. Y.; Tang, B. Z. Aggregate Science: From Structures to Properties, Adv. Mater. 2020, 2001457.

(46) Zhao, Z. J.; Lam, J. W. Y.; Tang, B. Z. Tetraphenylethene: a versatile AIE building block for the construction of efficient luminescent materials for organic light-emitting diodes. J. Mater. Chem. 2012, 22, 23726.

(47) Hong, Y.; Lam, J. W. Y.; Tang, B. Z. Aggregation-induced emission. Chem. Soc. Rev. 2011, 40, 5361.

(48) Mei, J.; Leung, N. L. C.; Kwok, R. T. K.; Lam, J. W. Y.; Tang, B. Z. Aggregation-Induced Emission: Together We Shine, United We Soar! Chem. Rev. 2015, 115, 11718.

(49) Wang, C.; Li, Z. Molecular conformation and packing: their critical roles in the emission performance of mechanochromic fluorescence materials. Mater. Chem. Front. 2017, 1, 2174.

(50) Huang, W.; Bender, M.; Seehafer, K.; Wacker, I.; Schröder, R. R.; Bunz, U. H. F. Novel Functional TPE Polymers: Aggregation-Induced Emission, $\mathrm{pH}$ Response, and Solvatochromic Behavior. Macromol. Rapid Commun. 2019, 40, 1800774 .

(51) Halász, A.; Barath, A.; Simon-Sarkadi, L.; Holzapfel, W. Biogenic amines and their production by microorganisms in food. Trends Food Sci. Technol. 1994, 5, 42.
(52) Pacquit, A.; Frisby, J.; Diamond, D.; Lau, K.; Farrell, A.; Quilty, B.; Diamond, D. Development of a Smart Packaging for the Monitoring of Fish Spoilage. Food Chem. 2007, 102, 466.

(53) Pablos, J. L.; Vallejos, S.; Munoz, A.; Rojo, M. J.; Serna, F.; Garcia, F. C.; Garcia, J. M. Solid Polymer Substrates and Coated Fibers Containing 2,4,6-Trinitrobenzene Motifs as Smart Labels for the Visual Detection of Biogenic Amine Vapors. Chem. - Eur. J. 2015, 21, 8733 .

(54) Syed, S. Recovery of gold from secondary sources-A review. Hydrometallurgy 2012, 115, 30.

(55) Gurung, M.; Adhikari, B. B.; Kawakita, H.; Ohto, K.; Inoue, K.; Alam, S. Selective Recovery of Precious Metals from Acidic Leach Liquor of Circuit Boards of Spent Mobile Phones Using Chemically Modifified Persimmon Tannin Gel. Ind. Eng. Chem. Res. 2012, 51, 11901-11913.

(56) Cao, W. X.; Dai, F. Y.; Hu, R. R.; Tang, B. Z. Economic Sulfur Conversion to Functional Polythioamides Through Catalyst-Free Multicomponent Polymerizations of Sulfur, Acids, and Amines. J. Am. Chem. Soc. 2020, 142, 978.

(57) Wu, X.; Lin, H.; Dai, F.; Hu, R.; Tang, B. Z. Functional Polyselenoureas for Selective Gold Recovery Prepared from Catalyst-Free Multicomponent Polymerizations of Elemental Selenium. CCS Chem. 2020, 2, 191.

(58) Lin, S.; Kumar Reddy, D. H.; Bediako, J. K.; Song, M.-H.; Wei, W.; Kim, J.-A.; Yun, Y.-S. Effective Adsorption of Pd(II), $\mathrm{Pt}(\mathrm{IV})$ and $\mathrm{Au}(\mathrm{III})$ by $\mathrm{Zr}(\mathrm{IV})$-Based Metal-Organic Frameworks from Strongly Acidic Solutions. J. Mater. Chem. A. 2017, 5, 13557.

(59) Shin, D.; Jeong, J.; Lee, S.; Pandey, B. D.; Lee, J.-c. Evaluation of Bioleaching Factors on Gold Recovery from Ore by Cyanide-Producing Bacteria. Miner. Eng. 2013, 48, 20

(60) Niu, G.; Zhang, R.; Shi, X.; Park, H.; Xie, S.; Kwok, R. T. K.; Lam, J. W. Y; Tang, B. Z. AIE luminogens as fluorescent bioprobes. Trend Anal. Chem. 2020, 123, 115769. 